TITLE:

\title{
CONSIDERATIONS ON THE SEGREGATION OF RIGHT AND LEFT HANDED TYPES IN PHYSALIA
}

AUTHOR(S):

Tokioka, Takasi

\section{CITATION:}

Tokioka, Takasi. CONSIDERATIONS ON THE SEGREGATION OF RIGHT AND LEFT HANDED TYPES IN PHYSALIA. PUBLICATIONS OF THE SETO MARINE BIOLOGICAL LABORATORY 1973, 20: 141-144

ISSUE DATE:

1973-12-19

URL:

http://hdl.handle.net/2433/175783

RIGHT: 


\title{
CONSIDERATIONS ON THE SEGREGATION OF RIGHT AND LEFT HANDED TYPES IN PHYSALIA ${ }^{1)}$
}

\author{
TAKASI TOKIOKA
}

Seto Marine Biological Laboratory, Sirahama, Japan

\begin{abstract}
After the predominating occurrences of the right handed type in stranded Physalia physalis var. utriculus LA MARTINIERE on beaches near the Seto Marine Biological Laboratory were recorded (1969, pp. 183-185), some more observations have been made additionally in a hope to see any biological significance of the two types of Physalia, especially to see the possibility of segregation of right and left handed types by wind in the actual open sea areas. In making these observations, I owed much to Mr. H. TANASE, one of the curators of the laboratory aquarium, and Miss Mié ToKIOKA for their kind help and information. I want to express here my hearty thanks for their kindness.
\end{abstract}

\section{Records}

(1) $10(12-32 \mathrm{~mm})$ colonies from the north beach near the Laboratory, September 17, 1969 (by information of TANASE). Pneumatophore length in mm.

Left handed (Right sailing) type only

\begin{tabular}{c|c|c}
$12-18 \mathrm{~mm}$ & $19-25 \mathrm{~mm}$ & $26-32 \mathrm{~mm}$ \\
\hline 4 & 4 & 2
\end{tabular}

(2) $10(8-38 \mathrm{~mm})$ colonies from the north beach near the Laboratory, April 9, 1971 (collected by TANASE). Pneumatophore length in $\mathrm{mm}$.

Right handed (Left sailing) type. . .9 colonies

\begin{tabular}{c|c|c}
$8-13 \mathrm{~mm}$ & $14-19 \mathrm{~mm}$ & $20-24 \mathrm{~mm}$ \\
\hline 7 & 0 & 2
\end{tabular}

Left handed (R. s.) type............... colony ( $38 \mathrm{~mm}$ long), $10 \%$ of the total.

(3) 2 (29 and $49 \mathrm{~mm}$ ) colonies from the south beach near the Laboratory, June 13, 1971 (collected by TANASE). Pneumatophore length in $\mathrm{mm}$.

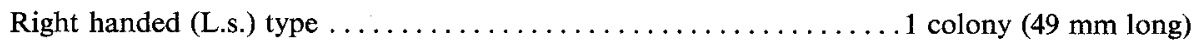

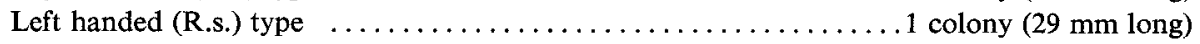

(4) $4(25-50 \mathrm{~mm})$ colonies from the north beach near the Laboratory, June 28, 1972 (collected by TANASE). Pneumatophore length in $\mathrm{mm}$.

Right handed (L.s.) type $\ldots \ldots \ldots \ldots \ldots \ldots \ldots \ldots \ldots \ldots \ldots$ colonies ( 25 and $32 \mathrm{~mm}$ long)

1) Contributions from the Seto Marine Biological Laboratory, No. 570 . 
Left handed (R.s.) type .2 colonies ( 42 and $50 \mathrm{~mm}$ long)

(5) $32(8-21 \mathrm{~mm})$ colonies from Banbei Beach on the south coast of the Bansyosaki Cape, about $700 \mathrm{~m}$ east of the Laboratory, August 3, 1972 (collected by Mié TokioKA). Pneumatophore length in $\mathrm{mm}$.

Right handed (L.s.) type .17 colonies

\begin{tabular}{c|c|c}
$8-11 \mathrm{~mm}$ & $12-16 \mathrm{~mm}$ & $17-21 \mathrm{~mm}$ \\
\hline 4 & 9 & 4
\end{tabular}

Damaged .15 colonies

(6) 309 (2-38 mm) colonies from Banbei Beach, August 26, 1972; drifted there, together with Velella, Porpita, some Janthina and a few Planes, by the southwest wind (by information and help of Mié TokioKA). Pneumatophore length in $\mathrm{mm}$.

Right handed (L.s.) type .294 colonies

\begin{tabular}{c|c|c|c|c}
$4-10 \mathrm{~mm}$ & $11-17 \mathrm{~mm}$ & $18-24 \mathrm{~mm}$ & $25-31 \mathrm{~mm}$ & $32-38 \mathrm{~mm}$ \\
\hline 45 & 144 & 65 & 28 & 12
\end{tabular}

Left handed (R.s.) type .12 colonies, $3.9 \%$ of the total.

\begin{tabular}{c|c|c|c}
$10 \mathrm{~mm}$ & $11-17 \mathrm{~mm}$ & $18-22 \mathrm{~mm}$ & $25-30 \mathrm{~mm}$ \\
\hline 1 & 4 & 5 & 2
\end{tabular}

Crest indiscernible 3 colonies $(2,4$ and $6 \mathrm{~mm}$ long respectively)

(7) $37(11-40 \mathrm{~mm})$ colonies from Banbei Beach, August 28, 1972 (collected by Mié ToKIOKA). Pneumatophore length in $\mathrm{mm}$.

Right handed (L.s.) type only

\begin{tabular}{c|c|c|c}
$11-17 \mathrm{~mm}$ & $18-24 \mathrm{~mm}$ & $25-31 \mathrm{~mm}$ & $32-40 \mathrm{~mm}$ \\
\hline 8 & 14 & 8 & 7
\end{tabular}

(8) $8(14-45 \mathrm{~mm})$ colonies from Banbei Beach, August 30, 1972 (collected by Mié TokioKa). Pneumatophore length in $\mathrm{mm}$.

Right handed (L.s.) type only

\begin{tabular}{c|c|c}
$14-19 \mathrm{~mm}$ & $24-25 \mathrm{~mm}$ & $45 \mathrm{~mm}$ \\
\hline 5 & 2 & 1
\end{tabular}

\section{Considerations}

Throughout the eight records presented here, (1) and (6) must be the most noticeable. The predominancy of the right handed type may be accepted generally. However, the occurrence of a pure population of the left handed (right sailing) type in September 1969 (1) shows the possibility that the predominating type might differ according to the location of the coast even on the Pacific side of Japan (or to seasons), if the effect of wind is admitted in the segregation of populations of right and left handed types. It is therefore urged to repeat similar observations on the east coast of Sikoku Island 
opposite Sirahama, where the Laboratory is situated, across the Kii Channel.

Results of examination on the materials of August 30, 1968 and August 26, 1972 (6) show evidently that the pneumatophore length is distributed quite similarly in the left handed type as in the right handed type. This may show that the wind will not be effectual at all in separating populations of the two types from each other.

Size distribution in the material of August 30, 1968 (after Tokıok A 1969, p. 185).

Right handed (L.s.) .........................676 colonies

\begin{tabular}{c|c|c|c}
$<10 \mathrm{~mm}$ & $11-15 \mathrm{~mm}$ & $16-20 \mathrm{~mm}$ & $21-25 \mathrm{~mm}$ \\
\hline 76 & 401 & 176 & 23
\end{tabular}

Left handed (R.s.) . . . . . . . . . . . . . . . . . . . . . . . 52 colonies

\begin{tabular}{c|c|c|c}
$<10 \mathrm{~mm}$ & $11-15 \mathrm{~mm}$ & $16-20 \mathrm{~mm}$ & $21-25 \mathrm{~mm}$ \\
\hline 5 & 25 & 17 & 5
\end{tabular}

It is certain that these two types will sail in different directions on the still water surface in a breeze. Theoretically, the deviation of the sailing course will become greater with the size of the pneumatophore. Then, the mode of the pneumatophore length in the left handed type in the two above-mentioned materials would have to be moved to the smaller side, if the wind were really effective to segregate the two types in the natural environments of the open sea, with the surface actually roughened by waves and swells and with the wind usually stronger than breeze.

Very frequently, swarms of Physalia will be found floating or stranded together with a number of Porpita, Janthina and some wood or bamboo pieces or inorganic matters such as pumice stones, which are all structured never to be segregated into separate groups by wind. This seems to show, too, that the wind will never be effectual in the natural environments in segregating populations of the two types of Physalia.

Thus, it may be concluded that the right and left handed types of Physalia are seemingly defined genetically. The occurrence of a pure population of the left handed type in the district may be taken rather to prove this than to show any special oceanographic or meteorological condition. Occurrences of much fewer left handed colonies among swarms of right handed colonies, at least in cases of August 30, 1968 and August 26, 1972, are very probably attributable to the variation in the same population rather than to mixing of two populations of different types, as the size distribution is quite similar in the two types, though it has not yet been explained why the percentage of the left handed type differs from case to case. Possibly, mixing of two different populations may occur sometimes.

Then, what can be the reason for the predominating occurrence of the right handed colonies generally on the Pacific coast of Japan? The great stock of Physalia in the western part of the North Pacific might consist mainly of the race in which the predominance of the right handed type is defined genetically. For full explanation of 
this, it must be indispensable that the whole life history of Physalia is traced in detail in that part of the ocean. Further, very close morphological comparison between the left handed colonies of pure left handed populations and those found in populations consisting mainly of right handed colonies is desirable, and also some speculation about the oceanographic and meteorological aspects at the age when Physalia was born on the earth is seemingly necessary to explain the problem more exactly.

\section{REFERENCE}

TokiokA, T. 1969. Droplets from the plankton net XXIII. The predominant type of Physalia in the Japanese waters. Publ. Seto Mar. Biol. Lab., XVII (3), pp. 183-185. (Further references are shown in this paper.) 